\title{
Preface: \\ A Career in Nutrition and Cardiovascular Disease: From Research to Results to Public Health Policy
}

\author{
Daan Kromhout, $\mathrm{PhD}, \mathrm{MSc}, \mathrm{MPH}^{1}$
}

Key Words: Cardiovascular disease, coronary heart disease, nutrients, diet, physical activity, smoking, public health policy

Recommended Citation: Kromhout D. Preface: a career in nutrition and cardiovascular disease: from research to results to public health policy. Public Health Reviews. 2012;33:351-62.

\section{BACKGROUND}

I began my studies with a Bachelor and a Master of Science in human nutrition followed by a $\mathrm{PhD}$ from 1974 to 1978 . My $\mathrm{PhD}$ research was focused on risk factors for cardiovascular disease (CVD) in children. Together with my colleague Frits van der Haar, we examined 2,500 school children measuring their height, weight and skinfold thicknesses in three towns in The Netherlands. We determined serum cholesterol and we did a dietary survey. In that study we found that five percent of children were obese and 25 percent had a higher serum total cholesterol level of more than $200 \mathrm{mg} / 100 \mathrm{ml}(5.2 \mathrm{mmol} / \mathrm{l}) .{ }^{1}$ This work was all descriptive and at that time I became more interested in questions such as what do the percentages mean and what is the meaning of high serum cholesterol levels in children? Can you translate that into future CVD risk?

During my $\mathrm{PhD}$ project, I attended a seminar of the International Society of Cardiology in Mexico in 1975. There was a stimulating faculty at the seminar including Professor Geoffrey Rose from the London School of Hygiene, Professor Jeremiah Stamler from Chicago and Professor Archie Cochrane from Cardiff after which The Cochrane Collaboration is named. Jeremiah Stamler gave a great talk about the Seven Countries Study

\footnotetext{
${ }^{1}$ Professor of Public Health Research, Division of Human Nutrition, Wageningen University, PO Box 8129, 6700 EV Wageningen, The Netherlands; e-mail: daan.kromhout@wur.nl.
} 
and I discovered in Mexico that the Study also contained a cohort from The Netherlands in the town of Zutphen.

I had not previously been told of the Zutphen Study and when I returned to the Netherlands I visited my first professor of nutrition, Cees den Hartog, and asked if he could tell me something about the Zutphen Study. It turned out that he was the Chair of the Advisory Committee for Zutphen and he told me that they had a problem because the Principal Investigator, Professor Van Buchem, had retired and they could not find anyone to head the study. The reason that they could not find someone was that, at that time, there was no formal training in epidemiology in The Netherlands and there were very few epidemiologists. Den Hartog told me, "If you are interested you can start tomorrow." I was interested in the study, but I was working on my $\mathrm{PhD}$ and I said that I would first like to finish my thesis. Two years later I finished my degree and moved from Wageningen University to the University of Leiden to the Institute of Social Medicine as an Assistant Professor of Nutrition and Epidemiology. I went back to Professor Den Hartog and we agreed that I would begin to work on the Zutphen Study.

\section{ZUTPHEN AND THE SEVEN COUNTRIES STUDY}

The reason that I was interested in Zutphen was that it was the only cohort of the 16 in the Seven Countries Study in which detailed information was repeatedly (every 5 years) collected on the diet of all the participants. In all other cohorts there was only a small sample selected at the baseline survey, generally between ten and 50 persons, and those men kept a dietary record for seven days. If they could not keep the records themselves, for instance of the farmers in Southern Europe some could not write at that time, there was a nutritionist who came to the home and collected the information for the records. These individuals also collected the equivalent amount of the foods they had eaten in containers that were sent to Minneapolis to the laboratory of Professor Ancel Keys, the Principal Investigator of the Seven Countries Study, for fatty acid analysis.

In Zutphen, the cross-check dietary history method was used to collect individual dietary data. In this method the dietician first asks, what is the general pattern of food consumption during a usual day? Then, based on the list of all foods consumed, it is determined if they are eaten on a daily, weekly, or monthly basis. And finally, a cross-check is made with the food that was bought for the whole family during a week. From this information, an average intake of individual foods is calculated. These are very detailed data: the interview takes generally between one and two hours and it takes 
another four to five hours to integrate the collected material into an average food consumption pattern. This is a very intensive process and a dietician can only do one person per day.

When I became the Principal Investigator of the study in 1978 almost nothing was computerized. With respect to the dietary history the only thing my predecessors had done in terms of analysis of the data was to calculate the total amount of energy and the grams of protein, fat and carbohydrates. My first job was to code all the dietary data and key them. I got some grants from the Nutrition Council and from other organizations to start digitalizing all the information. It took me two years before I finished that job and only then could I start data analysis.

In 1980 I got a grant from the Netherlands Organization for Research (NWO) to spent a year at the University of Minnesota with the Professors Ancel Keys and Henry Blackburn to extend my training in epidemiology and public health by following a MPH program. I also started data analysis of the Zutphen Study. Back in Leiden I began my research on diet and chronic diseases. This work led to the first paper I had in a high-impact journal, a paper on dietary fiber and coronary heart disease (CHD), cancer and all cause mortality in Zutphen published in The Lancet in $1982 .{ }^{2}$

In the 1980s data analysis of diet-disease relationships in prospective cohort studies was very time consuming. Computers were connected to the mainframe of the University. For the analysis that I was interested in, the relationship between diet and CHD, it was impossible to do the analysis during the daytime when the computer was used for simple things like a t-test. It was only in the evening or at night that we could run Cox regression. If you had made a mistake you came back the next day to correct the mistake and you had to wait for the next night. For people who are doing research now, it is almost unbelievable how it was done at that time.

As already mentioned, the Zutphen Study is part of the larger Seven Countries Study initiated and directed by Professor Ancel Keys from Minneapolis. He selected 16 cohorts in seven different countries (United States, Finland, The Netherlands, Italy, Greece, the former Yugoslavia and Japan). In total, 12,753 men aged 40-59 were examined between 1958 and 1964 and they have been followed for 40 years; currently we are updating the 50-year mortality data of the Study.

The first meeting I had with the investigators of the other countries was in 1979 on the island of Crete organized by the Greek colleagues; all the Principle Investigators of the studies were there. From that time I became involved not only in the Zutphen Study but also the Seven Countries Study. For instance, I coordinated with my colleague, Professor Alessandro Menotti from Italy, the 25-year mortality follow-up. In 1990 we put a 
database together in Rome containing risk factor data from the baseline, five-year and ten-year follow-up surveys in combination with the 25-year mortality data.

In 1985 I carried out a 25-year follow up of the Zutphen cohort. By that time, the men were between the ages of 65 and 84 and it had become a small cohort because of the 878 men examined in 1960 about half of them had died in 25 years. The original cohort from Zutphen was a random sample of men born between 1900 and 1920, so it was possible to add another random sample of men born in the same period. In this way I obtained a cohort of 900 elderly men who have been followed up until now. In the studies in the elderly we did not only follow the protocol for CVD epidemiology data collection, but also added information about different aspects of health. Besides the physical aspect of health, we are also interested in mental and social aspects of health. The work was repeated in 1990, 1995 and 2000 and thereafter only the mortality follow-up was continued. Similar surveys were carried out by my colleagues, Alessandro Menotti in Italy and Aulikki Nissinen in Finland. Jointly, we began what we called the Finland, Italy and Netherlands Elderly Study (FINE Study), which is the elderly component of the Seven Countries Study. Later on, our colleagues from Serbia (Srecko Nedeljkovic) and Crete (Anthony Kafatos) decided to carry out similar surveys. So, in total there are nine European cohorts that also have the elderly component. The FINE Study was later combined with the SENECA Study (the Survey in Europe on Nutrition in the Elderly: a Concerted Action) becoming the European Union funded Healthy Ageing: a Longitudinal study in Europe (HALE) project. The combined data provided a larger group and the SENECA Study also included elderly women and by combining the data the study got a broader perspective.

\section{RESULTS FROM ZUTPHEN AND THE SEVEN COUNTRIES STUDIES}

The Seven Countries Study was started by Ancel Keys to show whether the risk factors, that were known from and the Minnesota Business and Professional Men Study and the Framingham Study, were also predictive in other countries. This was the reason why Keys selected cohorts in the US, Northern and Southern Europe, and Japan. The results from the Seven Countries Study have shown that the strength of the association of risk factors such as serum cholesterol ${ }^{3}$ and blood pressure ${ }^{4}$ in relation to CHD mortality was similar in the different countries but the absolute risk was completely different. For example, the absolute risk to get a fatal CHD 
event in 25 years in relation to serum cholesterol and blood pressure was much higher in the US and Northern Europe than in Mediterranean Southern Europe and Japan. This means that need for treatment of high-risk persons is highest in the US and Northern Europe.

Two of my most frequently quoted papers are on diet and CHD. The first was on fish consumption and CHD mortality during 20 years of follow up and was published in the New England Journal of Medicine. ${ }^{6}$ What I found was that men who had been eating fish once or twice a week compared with those that did not eat fish had a 50 percent lower relative risk of fatal CHD. That was the first publication on fish consumption and CHD mortality using data from a prospective cohort study. When I analyzed the data in 1984 the only information we had on the subject was based on the comparison between the Inuit and the Danes. It was known that the Inuit had an extremely high consumption of seafood (about $400 \mathrm{~g} /$ day) and the Danes only $60 \mathrm{~g} /$ day and the incidence from CHD was ten times lower in the Inuit than in the Danes. That was a comparison on the population level and there was no information on the individual level. The average intake of fish in Zutphen men was only $20 \mathrm{~g} /$ day, 20 times lower than in the Inuit! It was a great surprise that we found such a strong association at a low level of fish consumption.

The second major finding was on flavonoids and CHD risk. The story behind that is that in $1986 \mathrm{I}$ got a request to present a paper on micronutrients and cancer for an International Life Sciences Institute (ILSI) conference. Besides a literature review, I decided also to analyze the relation between diet and lung cancer in the Zutphen Study. I found that vitamin C was inversely related to lung cancer even after taking smoking into account. I was also interested in which foods were responsible for this association and I expected for instance that oranges and potatoes would be protective, because these are rich sources of vitamin $\mathrm{C}$. When I did the analysis that was not the case; the strongest association was obtained for apples. Then I wondered, what are the bioactive compounds in apples that could be responsible for that?

To make a long story short, I went to Minneapolis to Professor Lee Wattenberg, an international renowned expert on anticarcinogens, and he suggested that the flavonoids could be the reason for the protective effect, because they are very strong anti-oxidants and are present in apples. This hypothesis sounded very attractive to me and I applied together with my colleague Dr. Peter Hollman for a grant for a $\mathrm{PhD}$ student to research flavonoids, working with the hypothesis that flavonoids would be protective in relation to cancer. However, flavonoids were not associated with either 
lung cancer or total cancer in the Zutphen Study. We then decided to analyze flavonoids also in relation to CHD, based on the hypothesis that anti-oxidants could prevent the oxidation of LDL cholesterol and could therefore be protective. In this case we found a strong inverse association between flavonoid intake and CHD and that was published in The Lancet. ${ }^{7}$

There are many more results from the Zutphen and Seven Countries Study. Alessandro Menotti, Henry Blackburn and I wrote a book summarizing the results of the Seven Countries Study over the first 35 years of follow-up. ${ }^{5}$ The book covers the major risk factors, diet and lifestyle factors, such as physical activity, smoking and alcohol in relation to CHD.

\section{THE ALPHA OMEGA TRIAL}

One of my main interests since the beginning of my career is the relation between fatty acids and CHD. When I found for the first time the inverse association between fish consumption and fatal CHD I wanted to replicate the results obtained in Zutphen. We found similar results in three independent cohort studies. I am also very much interested in the question whether associations obtained in prospective cohort studies are causal. I had kept up correspondence with Professor Archie Cochrane after the seminar in Mexico in 1975 and he always said to me that when I would like to become a real epidemiologist I had to carry out a randomized control trial (RCT). It took quite some time, but I eventually received funding from the Netherlands Heart Foundation, the National Institutes of Health in the US and Unilever Research in The Netherlands for a large RCT on omega-3 fatty acids and CHD in order to show that these fatty acids are the nutrients responsible for the protective effect of fish consumption.

I designed the Alpha Omega Trial in myocardial infarction patients who were randomized to receive four different types of margarines, using a $2 \mathrm{x}$ 2 factorial design. The margarines were identical in taste, color, odor and texture. One group received, on a daily basis, on average an additional amount of $400 \mathrm{mg}$ of the omega-3 fatty acids, eicosapentaenoic acid (EPA) and docosahexaenoic acid (DHA) (about the equivalent of eating fish twice a week). The second group received an additional $2 \mathrm{~g}$ of alpha-linolenic acid, a plant-based precursor of EPA-DHA found in plant oils such as soybean and linseed oil and could be a substitute to fish consumption if found to have an effect. The third group received a combination of both EPA-DHA and alpha-linolenic acid and the fourth a placebo. It was the first double-blind placebo-controlled trial with CVD endpoints and it lasted for ten years. 
In 2010, we published in the New England Journal of Medicine the main results from the trial in which we did not find an effect of omega-3 fatty acids on different CVD endpoints. ${ }^{8}$ Probably the reason for this was that the participants in the trial were all post-myocardial infarction patients with well-controlled cardiovascular risk factors; 90 percent received antihypertensives, 85 percent statins and 98 percent antithrombotics. So it was a very well-treated population that was at a low risk for new CVD events, which is most likely the reason that we did not find an effect. This highlights that it is extremely difficult in nutritional research to show causality. Starting with the association of fish consumption and fatal CHD, then pinpointing the omega- 3 fatty acids, and finally proving that they are causally related is a very difficult task.

Recently, we published a paper in Diabetes Care in which we described the results of a subgroup analysis in patients who, besides having had a myocardial infarction, also had diabetes. In that group we did show a strong protective effect of omega-3 fatty acids on the composite endpoint of sudden death, cardiac arrest and the implantation of cardioverterdefibrillators (ICDs). ${ }^{9}$ The reason is that patients who have had a myocardial infarction and in addition have diabetes are at high risk for this endpoint. These results are in accord with those of older secondary prevention trials in which treatment of cardiovascular risk factors was at a much lower level than nowadays. This demonstrates that changes in treatment during a period of more than 20 years should be taken into account in interpreting the results of trials.

\section{TRANSLATING RESEARCH INTO PUBLIC HEALTH PRACTICE}

The next question to be addressed should be how the results of research should be translated into public health practice. The case of fish consumption and fatal CHD is a very interesting one because not only the Alpha Omega Trial was negative, but at almost the same time the results of two other negative trials, the OMEGA trial from Germany and the SU.FOL.OM3 trial from France, were published. So if you have to advise the general population on fish consumption you are in a complex situation. The results of the prospective cohort studies show a clear inverse relation of eating fish once or twice a week with fatal CHD. Older trials confirmed the inverse association of fish consumption and fatal CHD, but the most recent trials did not show an effect except in subgroups. How do you integrate all the available evidence and what advice would you give? 
To my opinion the totality of evidence should be evaluated. A metaanalysis published in 2006 by Mozaffarian and Rimm from Harvard combined the results from the prospective cohort studies and the trials. They showed that $250 \mathrm{mg} /$ day of EPA-DHA was enough to provide protection from fatal CHD compared to not eating fish. Therefore, the advice is to eat fish once or twice a week. Meanwhile, the information from the recent trials that were negative can be explained by the fact that the patients in these trials were at a much lower absolute risk compared to the patients in the older trials. The problem is that in low-risk patients it is very difficult to show significant reductions in risk.

The negative results of the recently published trials on the effect of omega-3 fatty acids led to an intense debate among researchers. Based on the inconsistent results of the trials carried out so far, several colleagues concluded that in that case a public health recommendation on fish consumption can't be given. However, my view is that taking into account all the evidence on the omega-3 fatty acids and CHD, the advice to eat fish once or twice a week for prevention of CHD is justified.

\section{TRANSFORMING INFORMATION INTO POLICY: ROLES AT THE NATIONAL INSTITUTE OF PUBLIC HEALTH AND THE HEALTH COUNCIL OF THE NETHERLANDS}

The National Institute for Public Health (started 100 years ago with a focus on infectious diseases) is funded by the Ministry of Public Health. In the late 1980s when I started there, the Ministry became interested in the relation between lifestyle and chronic diseases. The Ministry asked the Institute in the 1990s to prepare a report about the state of health and possible future developments. What we did in the first document was to determine what the most important diseases were in the Netherlands from a public health perspective. After a lot of discussion we described the ten most important diseases from a mortality, prevalence and quality of life perspective. Our analysis showed that CVD, cancer and lung diseases are the most important in terms of mortality. However, from the point of view of the prevalence, chronic diseases such as diabetes and osteoarthritis are important and from a quality of life perspective, mental disorders such as anxiety disorders and depression could be added.

So what we tried to do was to get an overall picture of the major health problems in the country and we also tried to forecast what the important health problems would be in the next 20 years. If you take CVD for instance, the prediction was that the prevalence of these diseases would increase by 
more than 40 percent during that period. That sounds peculiar, because CVD mortality data show a continuous decrease in The Netherlands and in many western countries since the early 1970s. Thus, from a mortality standpoint, CVD are becoming less important. However, in terms of prevalence i.e., burden of disease CVD are becoming more important. This dichotomy, especially in the beginning, was not well understood. The public health reports were instrumental in clarifying complex issues for policy makers and to get a clear picture of what is going on in their country in terms of the burden of diseases.

Another important issue is, can you prevent chronic diseases? We calculated how many people in The Netherlands died due to cigarette smoking, to a poor diet, to physical inactivity, etc. From our work in the 1990s it became clear that of the total mortality in The Netherlands (which on a yearly basis is about 140,000 ) about 20,000 deaths could be attributed to smoking. We defined diet in terms of quantity and quality. The prevalence of obesity was used as an indicator of quantity and two nutrients (saturated and trans fat) and three foods (fish, fruit and vegetables) as indicators of quality. These two indicators for diet could explain a substantial part of the occurrence of chronic diseases. So we showed policy makers the importance of prevention and in later reports we also described the health care cost of the different diseases. This provided to policy makers information on which diseases were most costly to society and they could take this type of information into account in decision making.

While I was at the National Institute for Public Health, the final document that we put together was a report on diet called Our Food Our Health in which we integrated the information on diet and chronic diseases along with information on toxicological and microbiological aspects of foods. We showed that the potential health gain of changes from current diet to a diet based on the Guidelines for a Healthy Diet from the Health Council was much larger than the health gain from improvements on the microbiological and the toxicological aspects of foods. The reason for that document was to find out which measures in relation to the different aspects of food provided the largest health gain.

\section{CONCLUSIONS}

Research on diet and CVD and diet and health in general has been focused on nutrients and bioactive compounds. Personally, I became more and more interested in the health effects of foods and the total diet, because if you provide information about what is a healthy diet you have to tell the 
message in terms of foods and not in nutrients. Therefore, information on the associations of foods with different health outcomes are extremely important. If you tell to people who are interested in CVD prevention that they should not consume more than ten percent of energy from saturated fat, that message will not be understood because in that case they need to have knowledge about what saturated fat is, which foods are rich sources of saturated fat, etc. I think the integration of information on the health effects of nutrients and foods in prototypes of healthy diets is of paramount importance for prevention of chronic diseases. We found in the HALE project, a strong protective effect of a Mediterranean style diet, not only in relation to CHD and CVD but also to all-cause mortality. ${ }^{10}$

What I also want to stress is not only to focus on nutrients, foods and diets but also on other lifestyles factors like physical activity and smoking. My thinking about those lifestyle factors has become more and more integrated over time. So in terms of translating research to policy, I think, knowing what the health effects of foods are, is extremely important from a policy perspective. However, at the same time I like to know from a scientific point of view which nutrients or bioactive compounds are causing the inverse associations of e.g., fish and cocoa with CVD. ${ }^{6,11}$

Acknowledgements: Epidemiologic research is not the work of one person but is teamwork. I am very much indebted to the participants in the different studies, the many colleagues, $\mathrm{PhD}$ students and fieldworkers for their contribution to the results described here.

About the Author: Professor Daan Kromhout was trained in Human Nutrition at Wageningen University (MSc degree in 1974 and $\mathrm{PhD}$ degree in 1978) and in Epidemiology and Public Health at the University of Minnesota, Minneapolis, USA (MPH degree in 1981). In 1977 he became assistant professor at the Institute of Social Medicine, University of Leiden, and was Nutrition Foundation professor of Nutrition and Epidemiology from1984-1994. He served the National Institute for Public Health (RIVM) in Bilthoven from 1988-2005 as head of the Department of Epidemiology, director of the Public Health Research Division and director of the Nutrition and Consumer Safety Division. Since 1994 he is professor of Public Health Research at Wageningen University. He was appointed Vice-President of the Health Council of the Netherlands in 2005 and adjunct professor at the University of Minnesota in 2007. In 2009 he became Academy professor of the Royal Netherlands Academy of Arts and Sciences.

Dr. Kromhout's research is focused on diet, lifestyle, cardiovascular diseases and healthy aging. He is principal investigator of several national and international epidemiologic studies such as: the Zutphen Study, the Dutch contribution to the Seven Countries Study on diet, lifestyle and cardiovascular diseases of which he is co-chair; the HALE project on diet, lifestyle and healthy aging; and the Alpha Omega Trial on omega-3 fatty acids and cardiovascular diseases. 


\section{Acronyms List:}

$\mathrm{CHD}=$ Coronary heart disease

CVD $=$ Cardiovascular disease

DHA $=$ Docosahexaenoic acid

$\mathrm{EPA}=$ Eicosapentaenoic acid

FINE Study $=$ The Finland, Italy and Netherlands Elderly Study

HALE $=$ Healthy Ageing: a Longitudinal study in Europe

RCT $=$ Randomized control trial

SENECA Study = The Survey in Europe on Nutrition in the Elderly: a Concerted Action

\section{REFERENCES}

1. Kromhout D, van der Haar F, Hautvast JG. Coronary heart disease risk factors in Dutch schoolchildren--results of a pilot-study. Prev Med. 1977;6:500-13.

2. Kromhout D, Bosschieter EB, de Lezenne Coulander C. Dietary fibre and 10-year mortality from coronary heart disease, cancer, and all causes. The Zutphen study. Lancet. 1982;2:518-22.

3. Verschuren WM, Jacobs DR, Bloemberg BP, Kromhout D, Menotti A, Aravanis $\mathrm{C}$, et al. Serum total cholesterol and long-term coronary heart disease mortality in different cultures. Twenty-five-year follow-up of the seven countries study. JAMA. 1995;274:131-6.

4. van den Hoogen PC, Feskens EJ, Nagelkerke NJ, Menotti A, Nissinen A, Kromhout D. The relation between blood pressure and mortality due to coronary heart disease among men in different parts of the world. Seven Countries Study Research Group. N Engl J Med. 2000;342:1-8.

5. Prevention of Coronary Heart Disease: Diet, Lifestyle and Risk Factors in the Seven Countries Study. Kromhout D, Menotti A, Blackburn H (editors). Kluwer Academic Publishers: Norwell MA; 2002:1-267

6. Kromhout D, Bosschieter EB, de Lezenne Coulander C. The inverse relation between fish consumption and 20-year mortality from coronary heart disease. N Engl J Med. 1985;312:1205-9.

7. Hertog MG, Feskens EJ, Hollman PC, Katan MB, Kromhout D. Dietary antioxidant flavonoids and risk of coronary heart disease: the Zutphen Elderly Study. Lancet. 1993;342:1007-11.

8. Kromhout D, Giltay EJ, Geleijnse JM; Alpha Omega Trial Group. n-3 fatty acids and cardiovascular events after myocardial infarction. N Engl J Med. 2010; 363:2015-26.

9. Kromhout D, Geleijnse JM, de Goede J, Oude Griep LM, Mulder BJ, de Boer MJ, et al. n-3 fatty acids, ventricular arrhythmia-related events, and fatal myocardial infarction in postmyocardial infarction patients with diabetes. Diabetes Care. 2011;34:2515-20. 
10. Knoops KT, de Groot LC, Kromhout D, Perrin AE, Moreiras-Varela O, Menotti A, van Staveren WA. Mediterranean diet, lifestyle factors, and 10-year mortality in elderly European men and women: the HALE project. JAMA. 2004;292:1433-9.

11. Buijsse B, Feskens EJ, Kok FJ, Kromhout D. Cocoa intake, blood pressure, and cardiovascular mortality: the Zutphen Elderly Study. Arch Intern Med. 2006;166:411-7. 